The research program of the Center for Economic Studies (CES) produces a wide range of theoretical and empirical economic analyses that serve to improve the statistical programs of the U.S. Bureau of the Census. Many of these analyses take the form of CES research papers. The papers are intended to make the results of CES research available to economists and other interested parties in order to encourage discussion and obtain suggestions for revision before publication. The papers are unofficial and have not undergone the review accorded official Census Bureau publications. The opinions and conclusions expressed in the papers are those of the authors and do not necessarily represent those of the U.S. Bureau of the Census. Republication in whole or part must be cleared with the authors.

\title{
RESIDENT PERCEPTIONS OF CRIME:
}

\section{HOW SIMILAR ARE THEY TO OFFICIAL CRIME RATES?}

\author{
by
}

\author{
John R. Hipp * \\ University of California, Irvine
}

\section{CES 07-10 March, 2007}

All papers are screened to ensure that they do not disclose confidential information. Persons who wish to obtain a copy of the paper, submit comments about the paper, or obtain general information about the series should contact sang V. Nguyen, Editor, Discussion Papers, Center for Economic Studies, Washington Plaza II, Room 206, Bureau of the Census, Washington, DC 20233-6300, (301-763-1882) or INTERNET address sang.v.nquyen@census.gov. 


\begin{abstract}
This study compares the relationship between official crime rates and residents' perceptions of crime in census tracts. Employing a unique dataset that links household level data from the American Housing Survey metro samples over a period of 25 years (1976-2000) with official crime rate data for census tracts in selected cities during selected years, this large sample provides considerable ability to generalize the findings. I find that residents' perception of crime is most strongly related to official rates of tract violent crime. Models simultaneously taking into account both violent and property crime consistently found that property crime actually has a negative effect on perceived crime. Among types of violent crime, the robbery rate is consistently related to higher levels of perceived crime in the tract, whereas it appears a structural shift occurred in the mid-1980s in which aggravated assault and murder rates now impact perceptions of crime, even when taking into account the robbery rate.
\end{abstract}

Keywords: perceived crime, official rates of crime, violent crime, neighborhoods, longitudinal, census tract.

* The research in this paper was conducted while the author was a Special Sworn Status researcher of the U.S. Census Bureau at the Triangle Census Research Data Center. Research results and conclusions expressed are those of the author and do not necessarily reflect the views of the Census Bureau. This paper has been screened to ensure that no confidential data are revealed. 
Resident perceptions of crime

\section{Resident perceptions of crime: How similar are they to official crime rates?}

There is considerable interest in knowing the level of crime in a neighborhood.

Researchers would like to measure the amount of crime as a first step in understanding why some neighborhoods have more crime than others. Residents would like to know the amount of crime to make decisions on which neighborhoods to walk about in, whether to move out of a neighborhood, and which new neighborhood to move into. Police departments would like to know the amount of crime to help in deciding where to target resources when trying to eliminate crime. Despite this near universal interest in knowing the level of crime in a neighborhood, there is considerable uncertainty in how best to answer this question. About the only certainty regarding this issue is that there appears to be no ideal way to measure the amount of crime in a neighborhood.

Although there is no ideal way to measure the actual amount of crime in a neighborhood, three common approaches have evolved for measuring this construct: 1) using victimization surveys; 2) using counts of incidents officially reported to the police; 3) using reports of perceived crime by neighborhood residents. The first approach, using victimization surveys, is intuitively appealing, as it seems reasonable to suppose that those who have experienced crime are most able to report on its prevalence. Nonetheless, this approach is limited in that such data are subject to recall response biases (Cohen and Land 1984; Gove, Hughes, and Geerken 1985). As well, we need to know where the crime occurred: a resident reporting about a victimization that occurred in a different neighborhood of the city, or even a different city or state, is not providing information about the neighborhood they reside in. Thus, to the extent that any victims of crime in the neighborhoods of interest are not included in the sample, this will result in an underestimate of the actual crime in the neighborhood. An additional issue for studies 
Resident perceptions of crime

wishing to obtain estimates of the amount of crime in relatively small units of analyses such as blocks, block groups, or tracts, is that the relative rarity of experiencing crime events requires very large samples to obtain reasonable estimates of crime rates for small geographic areas. Without such blanket surveying, the estimates obtained in such analyses will have too much uncertainty to be useful for practical analysis.

As a result of this imprecision, the other two approaches are frequently used in neighborhood studies. Perhaps the most common research strategy employs official statistics of incidents reported to the police. While these data are relatively easy to collect from police departments, a well-known limitation is that not all incidents are reported to the police. This non-reporting occurs for various reasons. If the non-reporting is random, no bias would be introduced into estimates comparing the amount of crime across neighborhoods (other than the fact that the level of crime would be equally underestimated in all neighborhoods). On the other hand, to the extent that such non-reporting is related to the constructs of interest in the model, estimates of the effect of a measure predicting crime across neighborhoods will be biased.

Because of these limitations, some recent research employs the third approach to estimating the amount of neighborhood crime: asking residents to assess the amount of crime in the neighborhood. While relying on the crime assessment of any single respondent would almost certainly contain an undesirably large amount of measurement error, utilizing the reports of a number of residents in the tract allows constructing a more accurate measure. Such an approach uses the subjective assessments of crime by several respondents in the neighborhood to estimate the common perception of crime. For instance, Sampson, Raudenbush and Earls (1997) used item response theory (IRT) as one way to estimate such a model in their study of crime in Chicago. In another substantive context, Speizer and Bollen (2000) provide an example of the approach using structural equation modeling. 
Resident perceptions of crime

Given the increasingly frequent use of the latter two approaches—using official crime data or using respondents' reports of perceived crime-a natural question is how similar are their estimates of the amount of crime in a neighborhood? While we actually have very little evidence on this point, some preliminary findings seem to suggest that different measures of crime provide generally similar results. For instance, past studies using large units of analysis such as cities have compared the agreement between official crime reports and victimization surveys (Cohen and Land 1984; Gove, Hughes, and Geerken 1985), finding a general similarity. A study comparing the relationship between official crime rates and victimization rates for census tracts in Seattle found a correlation between the victimization rate and the official measures of .58 for burglary and .68 for robbery/assault (Bellair 2000). However, these studies do not directly address whether a common perception of crime is related to other crime measures. A study using geographic units the size of two census tracts employed all three measures as outcomescommon perception of crime, official crime rates, and victimization rate-and found that the structural characteristics of the study had relatively similar effects on each of these three outcomes (Sampson, Raudenbush, and Earls 1997). This suggests a fair amount of similarity between these measures, at least when measuring them at the geographic level of units approximately the size of two census tracts. A rare study viewing the relationship between victimization of burglary events and the perception of burglary as a problem in the neighborhood found a positive correlation, but focused on only ten neighborhoods from three different cities (Skogan and Maxfield 1981). Clearly, generalizing these results from ten neighborhoods requires considerable caution; in addition, asking specifically about a particular crime precludes understanding what residents are considering when asked a more general question about crime as a problem. Thus, such studies leave unanswered the question of how generalizable their results are to other cities, other time points, and questions about perception of general crime. 
Resident perceptions of crime

On a related note, we have little evidence of what type of crime is most important for fostering a perception of crime in the neighborhood. Note that the question of how much crime is perceived in the neighborhood is distinct from prior research focusing on fear of crime, or perceptions of one's own risk of crime, since it is asking simply about the existence of such crime (Rountree and Land 1996a; Rountree and Land 1996b; Wilcox, Quisenberry, and Jones 2003). Nonetheless, it is plausible to suppose that certain types of crime are particularly salient to residents in creating this perception. While Zimring (1997) has suggested that violent crime is particularly important for creating fear and uncertainty in the U.S., little systematic evidence exists if this fear of violent crime is translated into a general perception of crime in the neighborhood when surveying residents. Beyond the question of whether violent or property crime are most important for fostering a general perception of crime in the neighborhood is the more nuanced question of whether certain types of violent crime are more important. For instance, whereas murder is a crime with consequences of severe finality that may be particularly frightening, the relative infrequency of this type of crime compared to others, as well as the possible perception that it frequently occurs between persons who know one another, may reduce its effect on residents reporting their general perception of neighborhood crime. On the other hand, the violent crime of robbery implies both physical force as well as taking financial resources, and the fact that it often occurs in public places may lend it particular weight when residents assess the degree of crime in the neighborhood. And although the violent crime of aggravated assault does not include the taking of financial resources, the fact that it also generally occurs in public places, as well as a possible perception of greater irrationality (since it is not accompanied by taking financial resources) may give it particular weight in such assessments. The paucity of studies regarding these issues leaves these questions open. 
Resident perceptions of crime

Additionally, we have little evidence on whether the relative importance of these different crime types for fostering a perception of crime in the neighborhood has changed over time.

Given the minimal evidence regarding the relationship between official rates of crime in neighborhoods, and residents' common perception of neighborhood crime, this study seeks to fill this lacuna by comparing the degree of agreement between measuring crime in a census tract based on official reports of crime to the police and reported perceptions of crime of residents in the tract. I accomplish this with a unique dataset that I constructed by linking household level data from the American Housing Survey metro samples over a period of 25 years (1976-2000) with official crime rate data for census tracts in selected cities during selected years. The goal of the sample of crime data is not one of randomness to allow inference to a population of cities, but rather a convenience sample of data for a large number of census tracts across many cities over a long period of time to allow the greatest generalizability to these relationships of a large number of households nested within census tracts. Thus, the modeling strategy simply conditions out these differences across cities as a nuisance, as described more fully below. This study provides important advances to the literature by: 1) testing the relationship between official crime reports and tract perceived crime from residents in a large number of cities (24 different cities at various time points); 2) testing this relationship over a long time period using seven waves of data (using seven samples from 1976 to 1999). Thus, this study provides considerable generalizability of this relationship since it tests these effects over a large number of cities over a long period of time, as well as viewing whether there have been changes in these relationships over this period of time. 
Resident perceptions of crime

\section{Data}

Individual-level data from the American Housing Survey (AHS) metropolitan samples

The American Housing Survey (AHS) contains both a national sample of about 60,000 housing units every two years, as well as surveys of about 4,000 housing units from each of a large number of metropolitan areas across the U.S in various years. Every two years the AHS surveys a subset of the metropolitan areas: as a result, a given metropolitan area is surveyed approximately every four years. Because of this variability in the actual year of the survey, I am sometimes combining metropolitan areas from slightly different years. That is, whereas I have surveys from the “waves” 1976, 1979, 1983, 1987, 1991, 1995, and 1999, these “waves” actually contain the data for the nearest year in which a particular metropolitan area was surveyed. For instance, whereas in the wave 1987 some of the metropolitan areas were actually surveyed that year, some of the metropolitan areas were actually surveyed in 1985. This difference in the actual year is a minor issue in general, and is particularly unproblematic since I will condition out differences across metropolitan areas in the analyses, as I will describe more fully below.

The AHS asks respondents a series of three questions regarding crime in the neighborhood (as defined by the respondent): is crime a problem, is it so much of a problem that it's a bother, and is it such a bother that the respondent wishes to move. I combine these responses into a four point response where the respondent either replies "no" to all questions, replies “yes” to one, “yes” to two, or “yes” to all three.

\section{Crime data from several cities}

This study utilizes official crime data for census tracts in 24 cities over a period of 25 years. This crime data come from various sources, and are not a random sample of cities but rather a convenience sample of cities providing crime data for any years. Thus, the sample varies in the years of coverage, and the types of crime available for different cities in different 
years. Table 1 presents the number of households and tracts included in each of the samples. ${ }^{1}$ An advantage of using census tracts is that past studies have frequently used them to proxy for neighborhoods, they contain a mean of about 4,300 residents in 2000 (with 95\% of the tracts containing between about 1,400 and 8,000 persons), and they were initially constructed by the Census Bureau to be relatively homogeneous neighborhoods (Green and Truesdell 1937; Lander 1954). However, not all of my crime data is available for tracts. For instance, some of the crime data is only available for police beats, which on occasion may partially overlap more than one census tract. Thus, these data were apportioned into appropriate census tracts for that particular year, a process I describe in the appendix.

$$
<<<\text { Table } 1 \text { about here }>>>
$$

In all instances, I matched the official crime data to the closest wave of the AHS. For instance, if a city was sampled in 1985, they would be included in the 1987 wave of the AHS, but I included crime data from 1985 (actually, averaged over 1984, 85, and 86, as I describe next). Thus, the official crime data and the perception of crime data from the AHS are nearly always coterminous. $^{2}$

An additional complication is that the AHS residents were placed into 1980 census tracts by using special access to the Triangle Census Research Data Center (TCRDC). As a result, it was necessary to place all of the crime data into 1980 tracts. For some of the cities in older years, the data were already in 1980 tracts, requiring no additional action. For some cities, and for more recent years of data, the crime data were in 1990 or even 2000 tracts, requiring apportioning the data into 1980 census tracts. I describe how this was accomplished in the

\footnotetext{
${ }^{1}$ The cities included in the sample are: Amherst, Baltimore, Berkeley, Buffalo, Chicago, Cincinnati, Cleveland, Denver, El Cajon, Indianapolis, Los Angeles, Menlo Park, Milwaukee, National City, Philadelphia, Sacramento, San Diego, San Diego county, Seattle, St. Louis, St. Petersburg, Tampa, Washington, D.C., West Allis.

2 The rare exceptions were still very close. For instance, while I had households in Cleveland in 1979, the crime data come from 1980. Likewise, whereas I had households for Washington, D.C. in 1981, the crime data come from 1980. Given the strong stability in tract-level crime rates over adjacent years, these differences are likely minimal.
} 
Resident perceptions of crime

appendix. As a consequence of this, we should expect that the later years will have additional measurement error because of this need to place the crime data into 1980 tracts, suggesting that the relationship between the official crime rates and the common perception of crime may appear weaker in later years. This should be regarded simply as a methodological limitation, rather than an indication of a change in this relationship over time.

The key independent variables in the analysis measure the amount of crime in the tracts of the study. For each of these crime measures I calculated the number of crime events that occurred per 100,000 population and natural log transformed these variables to reduce the skew and minimize the possibility of outliers. Whenever possible, I also averaged these values over three years to minimize year-to-year fluctuations. I combined various types of crime into measures of violent crime (a sum of robbery, aggravated assault, murder) and property crime (a sum of burglary, motor vehicle theft, and larceny). ${ }^{3}$ I also estimated models using five key types of crime separately: aggravated assault, murder, robbery, motor vehicle theft, and burglary. These five vary along the dimensions of property/violent crime and personal/public (being defined on whether the crime generally occurs between people who know each other or generally between strangers). Aggravated assault is a violent crime that generally occurs between strangers; murder is a violent crime that often occurs between people who know each other; robbery is a combination of both violent and property crime (since it involves the threat of force, and the goal of obtaining something of value) that occurs between strangers (Cohen, Felson, and Land 1980); while motor vehicle theft and burglary are property crimes that usually occur between strangers. Testing these crime types separately provides insight into whether any particular type of crime is most important for fostering a perception of crime in the neighborhood

\footnotetext{
${ }^{3}$ I did not include rape as a component of the measure of violent crime given the well-known problems of reporting associated with this measure.
} 
Resident perceptions of crime

for residents. And testing them simultaneously allows assessing which of these crime types affects perceived crime, when accounting for the other types of crime.

Household and individual characteristics

To account for possible bias effects in assessing perceived crime and disorder, in some models identified below I included several individual- and household-level demographic measures. Since there may be gender differences in perceptions of the amount of crime and disorder, I included a dichotomous measure coded one for females. I captured SES with measures of household income (logged) and years of education of the respondent. To account for racial/ethnic differences, I included dichotomous indicators for African-Americans, Latinos, and other race (with whites as the reference category). ${ }^{4}$ I included an indicator of whether the respondent owned their residence, and the length of time in the residence, log transformed. To account for life course, I included a measure of the age of the respondent, dichotomous indicators for marital status (married, divorced, or widowed, with single as the reference category), and an indicator of whether they have children less than 18 years of age at home. I included a measure of the persons per room (log transformed), and an indicator of whether it is the household's first year in the residence (since such residents may be less aware of neighborhood problems).

\section{Methodology}

The models are estimated as hierarchical linear models. In this framework, the random intercept in this equation can be seen as the common perception of crime that is a latent predictor of the household assessments of crime in the neighborhood. Thus, the level one equation is:

$$
\mathrm{y}_{i k}=\Lambda_{1} \eta_{k}+\varepsilon_{i k}
$$

\footnotetext{
${ }^{4}$ For earlier years in which there were too few Latinos to estimate a separate effect, I collapsed them into the "other race/ethnicity" category.
} 
where $\mathrm{y}_{i k}$ is the combined four-point response in the AHS regarding the level of crime reported by the $i$-th respondent of $M$ respondents in the $k$-th tract, $\eta_{k}$ is the latent variable of common perception of crime in the tract, and $\varepsilon_{i k}$ is a disturbance term. ${ }^{5}$ Thus, this model posits that there is something "out there" in the environment causing all respondents in the tract to perceive more crime, and this correlation between the respondents on the same tract is the estimate of this common perception of crime.

In ancillary models, I am also able to take into account the possibility of systematic bias that may occur when responding to the crime question. Since certain types of people may systematically answer this question differently, I accounted for this by allowing several demographic measures to have a direct effect on the amount of perceived crime. The elaborated level one equation then becomes:

$$
\mathrm{y}_{i k}=\lambda \eta_{k}+\Gamma \mathrm{X}_{i k}+\varepsilon_{i k}
$$

where the previous model has been augmented by $\mathrm{X}$, a matrix of exogenous predictors with values for each individual $i$ of $I$ individuals in tract $k$, and $\Gamma$ which shows the effect of these predictors on the subjective assessment. Note that these residents are all assessing the level of crime while living in the same tract, and yet perceiving differing levels of crime. ${ }^{6}$ I am able to

\footnotetext{
${ }^{5}$ I tested this assumption of linearity of the 4-point Likert scale outcome in two ways. First, I estimated a model in which this outcome measure was log-transformed to assess the robustness of these findings. The results were extremely similar to the ones presented here, lending confidence to the results. Second, I estimated selected models as hierarchical ordered logit models. Again, the results were similar to those presented here. Given that this latter approach requires an estimation approach that does not always have favorable properties (Rodriguez and Goldman 1995), the fact that previous work suggests that treating a 4-point Likert scale as a linear measure will frequently produce similar results to an estimation technique treating the outcome as an ordered logit (Bollen and Barb 1981), and the fact that the coefficients in a model with the continuous measure have a more intuitive interpretation, I simply present the results of the hierarchical linear models here.

${ }^{6}$ Note that this could occur for many reasons: it is possible that some types of people just perceive more crime. It is also possible that some people take into account a larger geographic area when assessing this question, and therefore this colors their response. It is also possible that there are differences in the amount of crime in the various smaller blocks that constitute a census tract, and that residents are simply reporting accurately on the amount of crime in their micro-neighborhood. It is not my interest to adjudicate these possible explanations here, but rather I am simply interested in taking this possible difference in assessment into account in my analyses.
} 
Resident perceptions of crime

assess whether taking these perceptual differences into account provides a more accurate measure of the level of crime in the neighborhood than when failing to do so.

Of crucial interest in this study is assessing the degree of correspondence between the official crime reports and the reports by residents on their perceptions of the amount of crime in the neighborhood, and to accomplish this the household level one equation is augmented by estimating a tract level two equation as:

$$
\eta_{\mathrm{k}}=\beta \mathrm{Z}_{k}+\beta_{\text {city }} \mathrm{CITY}+\varepsilon_{k}
$$

where $\eta_{k}$ represents the overall perceived crime in tract $k$, Z represents the reported official rate of crime in tract $k$ (using measures of various types of crime), $\beta$ shows the effect of this official crime rate on overall perceived crime, CITY is a series of M-1 indicator variables for the M cities in that wave of data and has a $\beta_{\text {city }}$ effect on the perception of crime, and $\varepsilon_{k}$ is a disturbance for tract $k$. Thus, this model is testing the relationship between this common perception of crime by residents in the tract with the official rate of crime in the tract. I included indicators of the city the tracts come from to take into account differences across cities: if the research question was focused on variability of constructs across cities, one could treat these cities as a random intercept and include city-level predictors. Since I am not interested here in modeling this variability across cities, the safest strategy is to simply account for differences across cities through this series of indicator variables.

In this model, the variance explained at level two by the various types of official crime gives a measure of the association between official crime reports and the perception of crime in the neighborhood as reported by the sample of residents. In the multilevel framework, this variance explained can be computed as the difference in the amount of level two variance between the model of interest (the model including the official crime rate as a predictor of this common perception of crime) and an initial unconditional model (a model not including the 
Resident perceptions of crime

official crime rates; in this case, only the city indicator variables are included as predictors of the common perception of crime), and dividing this by the level two variance in this unconditional model (Raudenbush and Bryk 2002). This demonstrates the reduction in the amount of variance at level two after including the measure(s) of official crime rates. This variance explained in a multilevel model is analogous to an $\mathrm{R}^{2}$ measure (Raudenbush and Bryk 2002). If we then take the square root of this value, we obtain $\mathrm{R}$, or the degree of correlation between the official crime reported and this common perception of crime in the neighborhood.

I took into account missing data through the use of multiple imputation (Rubin 1987). Such an approach requires the less stringent assumption of missing at random (MAR) rather than the missing completely at random (MCAR) assumption of listwise deletion. By imputing five datasets, such an approach yields appropriate standard errors that take into account the uncertainty introduced by the nonresponse (Schafer 1997). The standard errors of the five imputations are then combined using the standard formulas to take into account the variability both within imputed datasets, and across datasets (Rubin 1987; Schafer 1997).

AHS National Neighborhood sub-sample: ancillary analyses

I also performed ancillary analyses using the special AHS national neighborhood subsample, which allows me to compare respondents on the same block assessing perceived crime. This special sub-sample contains approximately eleven households in each of 663 non-rural blocks across the United States in the years 1985, 1989, and 1993. To construct this sub-sample, the AHS initially randomly selected 663 housing units from the full AHS that were located in either urban or suburban locations in 1985. They then interviewed the ten closest neighbors of the initial respondent. While I do not have measures of official crime rates for this national subsample, it does allow me to: 1) compare the degree of correlation between residents assessing crime on the same block in this sub-sample with the degree of correlation between residents 
assessing crime in the same tract in my main samples; 2) allows me to estimate fixed effects models in which I compare the effect of a household's characteristics on their perception of crime compared to other residents perceiving crime on the same block. ${ }^{7}$ If we assume that these are accurate estimates of the degree of bias contained in responses to questions regarding the amount of crime in the neighborhood—since these are respondents living on the same block with different perceptions of the crime level—we can combine these estimated values with the characteristics of the households in my main sample to adjust the reported levels of perceived crime. Thus, in this approach I am adjusting the reported perceived crime of the household by rearranging equation 2 above, and taking expectations to yield:

$$
\hat{y}_{i j}=\mathrm{y}_{i j}-\Gamma_{\mathrm{X}} \mathrm{X}_{i j}
$$

where $\hat{y}_{i j}$ is the estimated perceived crime adjusted for these biasing effects, $\mathrm{y}_{i j}$ is the individual's assessment of neighborhood crime, $\Gamma_{\mathrm{X}}$ contains the parameters estimated in the pooled fixed effects models using the national sample of households nested in blocks, and $\mathrm{X}_{i j}$ contains the demographic characteristics of the households in the tract. Such an approach is not entirely unique, and others have adopted it, including Morenoff (2003).

\section{Results}

Reliability

I begin by assessing the reliability of these measures by estimating the degree of agreement between residents living on the same tract with the intra-class correlation. This is computed as the amount of variance at level two divided by the total variance (the sum of level one and level two variance) in the unconditional model. Again, the city indicator variables are

\footnotetext{
${ }^{7}$ Fixed effects models take into account the block clustering by including K-1 indicator variables for the K blocks. Thus, all differences between blocks are accounted for, and the model is simply comparing responses of residents on the same block. An identical model can be estimated (and does not consume so many degrees of freedom) by centering all the variables in the analysis based on their neighborhood mean values.
} 
included in this unconditional model. For the tract-level data from the metropolitan samples, the average intra-class correlation over the four waves of data is .046 when using the crime measure as the outcome, and .053 when using the measure of crime adjusted for the bias factors estimated in the block-level data, as seen in Table 2. These are relatively low values. On the other hand, the average intra-class correlation using three waves of block-level data from the AHS national neighborhood sub-sample is .21. These twin results suggest there is a fair degree of heterogeneity in the amount of crime across blocks within the same tract. Since I am unable to place the survey respondents into units of analysis smaller than census tracts, this suggests that this study testing the correlation between the official rate of crime in tracts with this common perception of crime will likely be somewhat lower than it would be if these measures were both available at some smaller unit of analysis, such as the block level.

$$
<<<\text { Table } 2 \text { about here }>>>
$$

\section{Relationship between the common perception of crime and official crime rates}

To assess the relationship between the rates of official crime and the common perception of crime in the tract, I begin by separately viewing the relationship between each type of official crime and tract-level perceived crime. Each row of Table 3 shows the variance explained in tract-level perceived crime by the particular official crime type. The first seven columns of Table 3 show the actual variance explained for the various waves (1976 through 1999), the eighth column shows the average variance explained for the crime type over these seven waves of data, and the last column shows the average correlation of this official measure of crime with the tract-level perceived crime (or R, the square root of the average variance explained). ${ }^{8}$

$$
<<<\text { Table } 3 \text { about here }>>>
$$

\footnotetext{
${ }^{8}$ I computed the simple average of the coefficients over these seven waves. Alternative approaches are possible: for instance, weighted averages could be constructed based on the sample size in each wave. Since the strength of these relationships may change over time simply due to the methodological artifact of placing the new official crime data into 1980 tracts (as described in the data section), I treat the seven waves equally when constructing these averages.
} 
Resident perceptions of crime

A striking finding from these initial models is that respondents reporting on their perception of crime in the neighborhood are more influenced by the level of official violent crime types than they are by the level of official property crime types. The weakest effect is shown for motor vehicle theft, which only explains on average about $11 \%$ of the variance in tract-level perceived crime over these seven waves of data. Thus, there is on average a .33 correlation between the level of motor vehicle theft in a tract and the common perception of crime reported by respondents over these seven waves. The relationship between burglary and tract-level perceived crime is only slightly stronger: it explains, on average, about $20 \%$ of the variance in tract-level perceived crime, a correlation of .44. On the other hand, the various types of violent crime are much more strongly related to this common perception of crime: while murder explains, on average, about $18 \%$ of the variance in tract-level perceived crime, aggravated assault explains about $25 \%$ of the variance and robbery explains over $33 \%$ of the variance. Thus, the official robbery rate in a tract is correlated, on average, .58 with the common perception of crime in the tract reported by survey respondents. This correlation between the robbery rate and the common perception of crime ranges from .44 in 1983 up to .74 in 1976. Note that whereas this value generally decreases over time, this likely reflects the methodological artifact of additional uncertainty during the latter time points introduced by apportioning the crime data into 1980 tracts, as described in the data section. This also suggests that the higher correlation values of the earlier years may be more representative of the true relationship.

Moving to the aggregated measures of property and violent crime, the story remains the same in that this common perception of crime has a much stronger relationship with the amount of violent crime in the tract. The aggregated property crime measure explains relatively little of the common perception of crime: on average over these seven waves it explains $10 \%$ of the 
Resident perceptions of crime

variance (a correlation of .32). In contrast, the official violent crime rate explains a considerable amount of the variance in common perception of crime: over these seven waves, on average, it explains about $37 \%$ of variance, and is correlated .60 with the common perception of crime of residents in the tract. These correlation values range from .46 in 1983 to .76 in 1976 . Note that these effects are found on particularly large samples_ranging from 2,148 households in 249 tracts in 1976 to 14,430 households in 1,936 tracts in 1995-and over seven waves of data. Thus, these averaged values are based on 44,766 households in 6,417 tracts at seven time points, lending considerable confidence to the findings.

\section{Taking into account individual-level bias in perceived crime assessments}

The results thus far have shown that the official rate of violent crime in the tract has the strongest relationship with the common perception of crime of residents in the tract. However, since there may be systematic effects in which certain types of households perceive more or less crime, I next take these household characteristics into account to see if they improve the correlation between this common perception of crime and the official violent crime rates. To the extent that taking into account these household characteristics improves this correlation, it could suggest that they are incorrectly clouding the judgments of certain types of individuals.

Alternatively, it could indicate that such residents live in different blocks within the same tract that are characterized by different levels of crime. Row 8 of Table 3 presents the results for the model testing the relationship between the official rate of violent crime and the common perception of crime when these household-level characteristics are included. As can be seen, taking into account these characteristics sharpens the relationship between the official violent crime rate and this common perception of crime: the official violent crime rate is now explaining, on average, $47 \%$ of the variance in this adjusted common perception of crime. Thus, 
Resident perceptions of crime

the average correlation between the official violent crime rate and the common perception of crime has increased from .60 in the unadjusted model (row 7) to .69 in this adjusted model (row 8). These correlation values for particular waves range from .56 in 1983 up to .83 in 1976. This suggests that the precision of the tract-level perceived crime measure can be sharpened if the researcher is able to take into account demographic characteristics of the respondent that are affecting the assessment.

Although taking into account the household's characteristics sharpens the estimate of perceived crime, a critique of this approach is that it requires information on the characteristics of the households in the tract as well as the official crime rate. This is because this solution is based on a simultaneous estimation procedure. However, in most instances the researcher will not have the official crime data, and thus is unable to adjust for the household demographic characteristics in such a manner-indeed, the very purpose of this study is to determine the degree of relationship between the common perception of crime and the official crime rate given that researchers often only have one or the other available. Can anything be done in this instance? I utilize the estimated coefficients from a fixed effects analysis of the AHS national neighborhood sub-sample to create adjusted perceived crime measures, as described above in equation 4.

Turning to the results, we see that this approach taking into account the biasing factors estimated using the national sample of households nested within blocks improves the relationship between the common perception of crime and the official rate of violent crime in the tract over the model that does not correct for these biasing effects. The official rate of violent crime now explains, on average, about $42 \%$ of the variance in the tract-level perceived crime over these seven waves, as seen in row 9. Thus, taking into account the bias estimates from the blocknesting sample improves the correlation between the official violent crime rate and the common 
perception of crime, on average, from .60 to .65 over these seven waves of data. This correlation ranges from .52 in 1983 to .81 in 1976.

\section{Considering the effects of different crime types simultaneously}

While the previous analyses viewed the relationship between the common perception of crime in the tract and official rates of various types of crime in sequential fashion, I next estimated models allowing the rates of various types of official crime to simultaneously predict the tract-level perceived crime. ${ }^{9}$ Thus, these analyses test whether the stronger effect of various types of violent crime on the common perception of crime compared to the various types of property crime remain when simultaneously including these effects. The results are resoundingly affirmative, as shown in Table 4: the robbery rate again appears most important for fostering a common perception of crime in the tract compared to the other types of crime. Taking a simple average over these seven waves of data, we see in the last column of Table 4 that the robbery rate is the only measure that is significantly related to the common perception of crime in the tract when including all of these crime types simultaneously. ${ }^{10}$ Indeed, the effect of robbery is significant in six of the seven waves, even when including the other four types of crime in the model simultaneously.

$<<<$ Table 4 about here $>>>$

\footnotetext{
${ }^{9}$ I tested for, and found no evidence of, excess collinearity. For the models including these five types of crime simultaneously, the largest VIF values are always less than 6. Thus, while there is a fair degree of correlation among these measures, and the standard errors are somewhat larger than the models including these measures separately, this collinearity is not so extreme that it causes problems in the estimation. Given that studies have suggested that VIF values above 10 constitute particular problems, these values do not suggest such problems. In the models including the aggregated measures of violent crime and property crime simultaneously, the largest VIF value is always less than 3 , suggesting no collinearity problems.

${ }^{10}$ I computed the simple average of the standard errors over these seven waves. Another approach for estimating the standard errors comes out of the multilevel literature and takes into account both the variance at each time point, as well as across each time point (for a more complete discussion of this, see Raudenbush and Bryk 2002). Since I suggest that the need to place residents into 1980 tracts may induce a methodological artifact that changes the measurement over time, I prefer adopting the simpler approach utilized here.
} 
Resident perceptions of crime

While the effect for robbery on the common perception of crime is robust over all waves of data, the effect for the other two measures of violent crime-murder and aggravated assaultshow a definite trend over this time period. Whereas these measures show little effect in the earlier waves, they are now important predictors of commonly perceived crime, even controlling for the robbery rate, in recent years. It is notable that whereas there was no significant relationship between aggravated assault and perceived crime in the first four waves (up through 1987), in the three waves of the 1990's it shows an effect very similar in size to that of robbery. This is an important change, and given the large sample size of these more recent waves of data suggests that this is not simply a statistical artifact. Instead, the evidence here implies a particular structural change in which the aggravated assault rate is now more important for assessing the amount of crime in the neighborhood in the 1990's compared to the mid-1970's and 1980's. Note that this significant effect is not simply due to the larger sample sizes in recent years, as the coefficients for aggravated assault in the earlier waves were actually slightly negative. While the effects of murder are more modest compared to the other two measures of types of violent crime, they show a pattern similar to that of aggravated assault in that the size of the effect has increased in more recent waves. The effect of the murder rate on the common perception of crime has jumped higher in the late 1990’s. Thus, whereas robbery alone explained the common perception of crime from the mid-1970's through the 1980's, in the 1990’s it appears that the rate of murder and aggravated assault also help explain why residents perceive crime in the neighborhood.

These models also highlight that, when controlling for these three types of violent crime, there is virtually no evidence that the two types of property crime measured here-burglary and motor vehicle theft—have a positive effect on the common perception of crime. Over these seven waves of data, for 38,546 household years in 5,711 tract years, there is not a single 
Resident perceptions of crime

instance in which the rate of these types of property crime significantly increases the common perception of crime. In fact, in a couple of waves they actually have a counterintuitive negative effect. This reinforces the notion that it is violent crime that is important for the perception of crime in the neighborhood, and not property crime (Zimring 1997).

\section{Adjusting for individual-level biases}

I next estimated models simultaneously testing the effects of these rates of various types of crime for the outcome of perceived crime that is adjusted for individual-level biases. These models using the coefficients from the block-level national neighborhood sub-sample to adjust the perception of crime reported based on the demographic characteristics of the household show broadly similar results to the models failing to adjust for such biases. Once again, the most consistent predictor of perceived crime is the robbery rate in the tract, as seen in Table 5. For six of the seven waves, the robbery rate is significantly positively related to the common perception of crime in the tract, even controlling for these other crime types. The size of these effects is consistently stronger than those found in the models not adjusting for individual-level biases.

$$
<<<\text { Table } 5 \text { about here }>>>
$$

We again see evidence that the effect of murder and aggravated assault has increased in the waves during the 1990's. In fact, the change in this effect appears even sharper in these models accounting for household-level biases. Beginning in 1987, the effects of aggravated assault rates and murder rates for perceived crime jumped up. This even more clearly suggests that in the mid- to late-1980's there was a structural shift in which assault rates and murder rates became more salient for residents when assessing the degree of crime in the neighborhood. While robbery entails the taking of something of value, it is notable that these other two violent crime measures are pure assaults upon the person. This change reinforces the notion that an 
Resident perceptions of crime

overall measure of the amount of violent crime in the tract will have a particularly strong effect on the common perception of crime. Again, there is virtually no evidence here that the property crimes of burglary or motor vehicle theft positively affect the common perception of crime when controlling for these types of violent crime.

Simultaneous effects of aggregated violent and property crime

I next directly test the relative effect of the aggregated violent crime and property crime measures by simultaneously including them in the model. The findings are robust: aggregated violent crime consistently has a strong positive effect on the common perception of crime, whereas aggregated property crime shows virtually no significant positive effect in these models simultaneously controlling for the violent crime rate, as seen in the top half of Table 6. In every one of these seven waves of data, aggregated violent crime has a significant positive effect on perceived crime, whereas aggregated property crime never has a positive effect, and frequently has a significantly negative effect. This is an extremely robust finding over a large sample (39,760 household years and 5,817 tract years) over a long period of time (seven waves over 25 years). And these effects are even sharper and stronger in the models taking into account possible bias on the part of residents in reporting perceived crime, as shown in the bottom half of Table 6.

$<<<$ Table 6 about here $>>>$

What do we make of the apparent puzzle that aggregated property crime frequently has a negative effect on perceived crime? While one might suppose that a simple explanation for the negative effect of property crime is simply a statistical one of excess collinearity, such is not the case here. The largest VIF values are always less than 3, suggesting no excess collinearity. Additionally, whereas one clue to the existence of collinearity is little or no increase in the explained variance of the model when adding the second measure, these models including both 
violent and property crime simultaneously explain considerably more variance (results not shown). A strict interpretation suggests that adding more property crime events in a neighborhood decreases the common perception of crime. One speculation is that residents in neighborhoods high in both violent and property crime adapt to this high crime by altering their behavioral patterns, making this crime less salient. In contrast, residents in neighborhoods with low property crime may find increasing levels of violent crime particularly frightening.

Finally, I compiled a table of the above analyses in which I compare the variance explained in the models using these varying combinations of rates of official crime types to explain the common perception of crime in a tract. ${ }^{11}$ It is notable that the variance explained increases in models including these crime types simultaneously compared to the models including them separately: whereas the best predictor of common perception of crime not adjusted for individual-level biases_robbery — explained, on average, 33.5\% of the variance, and the aggregated measure of violent crime explained, on average, $36.4 \%$ of the variance, the models including official crime types simultaneously explained, on average, $40.4 \%$ of the variance, as seen in Table 7. The model simultaneously including violent and property crime explained a similar amount of variance: $40.8 \%$. A similar pattern emerged in the models using the outcome of perceived crime adjusted for individual-level biases: whereas the aggregated measure of violent crime explained, on average, $41.7 \%$ of the variance, the models including the various crime types simultaneously explained $46.5 \%$ of the variance, and the model including aggregated violent and property crime simultaneously explained $47.7 \%$ of the variance. Thus, the models taking into account individual-level biases yield a common perception of crime that is correlated, on average, .69 with the combined violent and property crime composition of the tract. These correlation values range from .57 in 1983 to .86 in 1976.

\footnotetext{
${ }^{11}$ Note that these comparisons are not strictly comparable since the sample sizes fluctuate in some instances. Nonetheless, the same pattern of results holds up if the comparisons are conducted on a constant set of census tracts (results not shown).
} 
Resident perceptions of crime

$<<<$ Table 7 about here $>>>$

\section{Conclusion}

This study provides an important contribution to the criminological community by addressing a fundamental question: what is the relationship between residents' perception of crime in a census tract and the reported official crime rate? There is scant evidence regarding this question, and this study provided evidence from a large sample of households living in 24 cities over a 25 year period. Thus, the results of this sample provide considerable ability to generalize to households in other cities. The tract-level perceived crime was correlated, on average, about .64 with the dual measures of aggregated violent and property crime. And this average correlation was improved to .69 when taking into account the household's demographic characteristics that may bias these perceptions of crime.

A key finding of this large study is that residents who report on their perception of crime in the neighborhood are most influenced by the official rate of violent crime types. This is consistent with the hypothesis of Zimring (1997) that residents are most fearful of, and hence respond most viscerally to, violent crime events. One particularly notable finding was that models simultaneously including measures of both aggregated violent and property crime always found a strong positive effect of violent crime on perceptions of crime over these seven waves, and simultaneously found that property crime always had a negative effect on perceptions of crime. Thus, there is no evidence here that property crime increases perceived crime once taking into account the level of violent crime in the tract. Moreover, the findings actually suggest that for two tracts with high rates of violent crime, the tract with a higher rate of property crime actually induces less perceived crime than does the tract with less property crime. One possibility is that residents in neighborhoods with high rates of both property and violent crime adapt to this environment in various ways, which then reduces their perception of the threat of 
Resident perceptions of crime

crime. In contrast, residents in neighborhoods with low or average rates of property crime may find higher violent crime rates particularly troubling. While clearly speculative, the robustness of this relationship in this large sample over a long time period suggests an important avenue for future research.

Another key finding of this study is that, when including the key types of violent crime simultaneously, different patterns were detected. Whereas the robbery rate shows a robust relationship with perceived crime that is relatively constant over this time period, the aggravated assault and murder rates showed a definite trend over this period. That is, whereas in the earlier years the robbery rate alone appeared to explain most of the variability in tract-level perceived crime, it appears that a structural shift occurred in the mid-1980s in which the aggravated assault and murder rates also became important for explaining perceptions of crime. As to why aggravated assault and murder rates now help to explain perceived crime when taking into account the robbery rate is an open question. The 1980's were a period of important macrostructural shits in the U.S.: the dismantling of the social welfare programs during the Reagan presidency was one particular shift. The rise of the war on drugs was another large shift. Either of these may have increased the saliency of these other types of violent crime. While clearly speculative, this suggests another avenue for future research.

While this study provides considerable evidence on the relationship between official crime rates and residents' perceptions of crime when both are measured at the tract level, future studies will want to test this relationship at other levels of aggregation. For instance, the findings reported here of considerably greater agreement among residents of the same block in reporting perceived crime compared to residents in the same tract suggests that aggregating to the level of the tract may be too large a unit of analysis. To the extent that blocks within the same tract vary in their level of crime, aggregating both official crime rates and perceptions of crime to this level 
Resident perceptions of crime

may diminish the size of this relationship. That is, while this study found a fairly high average correlation (about .7) between perceived crime and measures of aggregated violent and property crime over these seven waves of data, this relationship may be even sharper if one is able to measure both at smaller units such as blocks or block groups. At the same time, this provides a cautionary note for those performing analyses on data aggregating such measures to units of analysis even larger than census tracts.

The bottom line is that there is a fairly strong relationship between the reports of perceived crime by residents in a neighborhood and the official rates of violent crime reported to the police. This correlation of nearly .7 over this large sample of tracts over a 25 year period suggests a robust relationship. And even this value may be underestimated due to using census tracts as the unit of analysis: to the extent that there is heterogeneity in official crime rates and perceived crime across blocks within a particular tract, this relationship may be even stronger in smaller units of analysis. These findings highlight that whereas any single respondent may provide an assessment of neighborhood crime that has considerable measurement error, combining the responses of several respondents provides us information that correlates considerably with the official rate of violent crime in the neighborhood. Thus, dismissing such reports by residents as simply being perceptions of crime as opposed to "real” levels of crime seems misguided, as such residents seem to do a reasonable job of assessing the crime that exists in a neighborhood, at least as compared to official rates of crime. 
Resident perceptions of crime

\section{References}

Bellair, Paul E. 2000. "Informal Surveillance and Street Crime: A Complex Relationship." Criminology 38:137-167.

Bollen, Kenneth A. and Kenney H. Barb. 1981. "Pearson's R and Coarsely Categorized Measures." American Sociological Review 46:232-239.

Census, Bureau of the. 1987. "Census of Population and Housing, 1980: 1980-1970 Tract Comparability File." vol. 2005: Bureau of the Census: housed at the Odum Institute for Research in the Social Sciences, UNC-Chapel Hill.

—. 2000. "Census Tract Relationship File." vol. 2005: Bureau of the Census: housed at the Odum Institute for Research in the Social Sciences, UNC-Chapel Hill.

Census, United States Department of Commerce. Bureau of the. 1990. "Census of Population and Housing, 1990 [United States]: Tiger/Census Tract Comparability File." vol. 2005: Washington, DC: U.S. Dept. of Commerce, Bureau of the Census [producer], 1992. Ann Arbor, MI: Inter-university Consortium for Political and Social Research [distributor], 1992.

Cohen, Lawrence E., Marcus Felson, and Kenneth C. Land. 1980. "Property Crime Rates in the United States: A Macrodynamic Analysis, 1947-1977; with Ex Ante Forecasts for the Mid-1980s." American Journal of Sociology 86:90-118.

Cohen, Lawrence E. and Kenneth Land. 1984. "Discrepancies between Crime Reports and Crime Surveys." Criminology 22:499-530.

Gove, Walter R., Michael Hughes, and Michael Geerken. 1985. "Are Uniform Crime Reports a Valid Indicator of the Index Crime? An Affirmative Answer with Minor Qualifications." Criminology 23:451-501.

Green, Howard Whipple and Leon E. Truesdell. 1937. Census Tracts in American Cities. Washington, D.C.: Dept. of Commerce, Bureau of the Census.

Lander, Bernard. 1954. Towards an Understanding of Juvenile Delinquency. New York: Columbia.

Morenoff, Jeffrey D. 2003. "Neighborhood Mechanisms and the Spatial Dynamics of Birth Weight." American Journal of Sociology 108:976-1017.

Raudenbush, Stephen W. and Anthony S. Bryk. 2002. Hierarchical Linear Models: Applications and Data Analysis, vol. 1, Edited by J. DeLeeuw and R. A. Berk. Thousand Oaks: Sage.

Rodriguez, German and Noreen Goldman. 1995. "An Assessment of Estimation Procedures for Multilevel Models with Binary Responses." Journal of the Royal Statistical Society. Series A 158:73-89. 
Rountree, Pamela Wilcox and Kenneth C. Land. 1996a. "Burglary Victimization, Perceptions of Crime Risk, and Routine Activities: A Multilevel Analysis across Seattle Neighborhoods and Census Tracts." Journal of Research in Crime and Delinquency 33:147-180.

—. 1996b. "Perceived Risk Versus Fear of Crime: Empirical Evidence of Conceptually Distinct Reactions in Survey Data." Social Forces 74:1353-1376.

Rubin, Donald B. 1987. Multiple Imputation for Nonresponse in Surveys. New York: Wiley.

Sampson, Robert J., Stephen W. Raudenbush, and Felton Earls. 1997. "Neighborhoods and Violent Crime: A Multilevel Study of Collective Efficacy." Science 277:918-924.

Schafer, Joseph L. 1997. Analysis of Incomplete Multivariate Data. New York: Chapman and Hall.

Skogan, Wesley G. and Michael G. Maxfield. 1981. Coping with Crime: Individual and Neighborhood Reactions, vol. 124. Beverly Hill, CA: Sage.

Speizer, Ilene S. and Kenneth A. Bollen. 2000. "How Well Do Perceptions of Family Planning Service Quality Correspond to Objective Measures? Evidence from Tanzania." Studies in Family Planning 31:163-177.

Taylor, Ralph B., Sidney N. Brower, and Whit Drain. 1979. Toward a Neighborhood-Based Data File: A Map of Baltimore Neighborhoods. Baltimore, MD: Center for Metropolitan Planning and Research.

Wilcox, Pamela, Neil Quisenberry, and Shayne Jones. 2003. "The Built Environment and Community Crime Risk Interpretation." Journal of Research in Crime and Delinquency 40:322-345.

Zimring, Franklin E. 1997. Crime Is Not the Problem. New York: Oxford. 
Resident perceptions of crime

\section{Tables and Figures}

Table 1. Number of households and tracts in each sample used in the analyses

\begin{tabular}{|c|c|}
\hline Sample & Number of households/tracts \\
\hline a & 2,148 households in 249 tracts \\
\hline $\mathrm{b}$ & 1,052 households in 139 tracts \\
\hline c & 3,749 households in 830 tracts \\
\hline d & 3,065 households in 342 tracts \\
\hline e & 2,080 households in 229 tracts \\
\hline $\mathrm{f}$ & 4,555 households in 553 tracts \\
\hline g & 2,060 households in 253 tracts \\
\hline $\mathrm{h}$ & 6,514 households in 1157 tracts \\
\hline $\mathrm{i}$ & 3,017 households in 334 tracts \\
\hline j & 2,007 households in 228 tracts \\
\hline $\mathrm{k}$ & 2,075 households in 245 tracts \\
\hline 1 & 4,938 households in 961 tracts \\
\hline $\mathrm{m}$ & 3,255 households in 414 tracts \\
\hline $\mathrm{n}$ & 835 households in 139 tracts \\
\hline 0 & 5,299 households in 1054 tracts \\
\hline $\mathrm{p}$ & 7,460 households in 1465 tracts \\
\hline $\mathrm{q}$ & 6,869 households in 1,359 tracts \\
\hline $\mathrm{r}$ & 6,102 households in 1332 tracts \\
\hline $\mathrm{s}$ & 8,607 households in 2,061 tracts \\
\hline $\mathrm{t}$ & 14,430 households in 1936 tracts \\
\hline $\mathrm{u}$ & 13,118 households in 1803 tracts \\
\hline $\mathrm{v}$ & 14,496 households in 2,535 tracts \\
\hline $\mathrm{w}$ & 11,391 households in 1677 tracts \\
\hline $\mathrm{x}$ & 11,876 households in 1866 tracts \\
\hline $\mathrm{y}$ & 10,884 households in 1525 tracts \\
\hline
\end{tabular}

Note: Sample is denoted throughout the Tables by the sample letter indicated in this table. 
Table 2. Estimates of intra-class correlation for tract-level data from the AHS metro samples, and block-level data from the AHS national sample.

$\begin{array}{lrrrrrrrr} & & & & & & & \\ \text { Metro tract samples } & \mathbf{1 9 7 6} & \mathbf{1 9 7 9} & \mathbf{1 9 8 3} & \mathbf{1 9 8 7} & \mathbf{1 9 9 1} & \mathbf{1 9 9 5} & \mathbf{1 9 9 9} & \text { Average } \\ \text { Perceived crime } & 0.047 & 0.062 & 0.065 & 0.041 & 0.042 & 0.057 & 0.043 & 0.051 \\ \text { Perceived crime, adjusted } & 0.052 & 0.070 & 0.068 & 0.049 & 0.050 & 0.065 & 0.047 & 0.057 \\ & & & & & & & & \text { Average } \\ \text { National block sample } & \mathbf{1 9 8 5} & \mathbf{1 9 8 9} & \mathbf{1 9 9 3} & & & & & 0.212 \\ \text { Perceived crime } & 0.191 & 0.230 & 0.215 & & & & \end{array}$




\section{Resident perceptions of crime}

Table 3. Outcome of perceived crime as the outcome, reporting the R-square when using various official crime types

\begin{tabular}{|c|c|c|c|c|c|c|c|c|c|c|c|c|c|c|c|c|}
\hline & 1976 & & 1979 & & 1983 & & 1987 & & 1991 & & 1995 & & 1999 & & Avg & $\mathbf{R}$ \\
\hline \multicolumn{17}{|l|}{ Property crime types } \\
\hline 1 Burglary & 0.328 & $\mathrm{a}$ & 0.278 & $\mathrm{f}$ & 0.151 & $\mathrm{i}$ & 0.165 & $\mathrm{~m}$ & 0.225 & $\mathrm{p}$ & 0.128 & $\mathrm{t}$ & 0.097 & $\mathrm{x}$ & 0.196 & 0.443 \\
\hline 2 Motor vehicle theft & 0.152 & $\mathrm{a}$ & 0.085 & f & 0.135 & $\mathrm{i}$ & 0.097 & $\mathrm{~m}$ & 0.169 & $\mathrm{r}$ & 0.092 & u & 0.051 & $\mathrm{x}$ & 0.112 & 0.334 \\
\hline \multicolumn{17}{|l|}{ Violent crime types } \\
\hline 3 Robbery & 0.553 & a & 0.355 & f & 0.196 & $\mathrm{i}$ & 0.313 & $\mathrm{~m}$ & 0.364 & $\mathrm{r}$ & 0.270 & u & 0.291 & $\mathrm{x}$ & 0.335 & 0.578 \\
\hline 4 Aggravated assault & 0.266 & $\mathrm{~b}$ & 0.178 & g & 0.073 & $\mathrm{k}$ & 0.301 & $\mathrm{~m}$ & 0.396 & $\mathrm{r}$ & 0.261 & u & 0.258 & $\mathrm{x}$ & 0.248 & 0.498 \\
\hline 5 Murder & 0.224 & c & 0.169 & h & 0.062 & 1 & 0.192 & o & 0.165 & s & 0.184 & $\mathrm{v}$ & 0.236 & y & 0.176 & 0.420 \\
\hline \multicolumn{17}{|l|}{ Aggregated crime } \\
\hline 6 Violent crime & 0.573 & $\mathrm{a}$ & 0.408 & d & 0.214 & $\mathrm{i}$ & 0.395 & $\mathrm{~m}$ & 0.382 & $\mathrm{p}$ & 0.264 & $\mathrm{t}$ & 0.312 & $\mathrm{w}$ & 0.364 & 0.603 \\
\hline 7 Property crime & 0.144 & a & 0.129 & e & 0.080 & $\mathrm{j}$ & 0.031 & $\mathrm{n}$ & 0.161 & $\mathrm{q}$ & 0.097 & $\mathrm{t}$ & 0.062 & $\mathrm{w}$ & 0.101 & 0.317 \\
\hline \multicolumn{17}{|c|}{ Aggregated crime, taking into account household characteristics } \\
\hline 8 Violent crime, adding individual-level predictors & 0.695 & a & 0.513 & d & 0.314 & $\mathrm{i}$ & 0.566 & $\mathrm{~m}$ & 0.425 & $\mathrm{p}$ & 0.329 & $\mathrm{t}$ & 0.444 & $\mathrm{w}$ & 0.469 & 0.685 \\
\hline 9 Violent crime, adjusting outcome for individual bias & 0.660 & a & 0.468 & d & 0.275 & $\mathrm{i}$ & 0.462 & $\mathrm{~m}$ & 0.409 & $\mathrm{p}$ & 0.284 & $\mathrm{t}$ & 0.362 & w & 0.417 & 0.646 \\
\hline \multicolumn{17}{|l|}{ Percent variance at level two } \\
\hline 10 Perceived crime measure & 0.047 & a & 0.062 & d & 0.065 & $\mathrm{i}$ & 0.041 & $\mathrm{~m}$ & 0.042 & $\mathrm{p}$ & 0.057 & $\mathrm{t}$ & 0.043 & $\mathrm{w}$ & 0.051 & \\
\hline 11 Perceived crime measure adjusted for individual bias & 0.052 & a & 0.070 & d & 0.068 & $\mathrm{i}$ & 0.049 & $\mathrm{~m}$ & 0.050 & $\mathrm{p}$ & 0.065 & $\mathrm{t}$ & 0.047 & w & 0.057 & \\
\hline
\end{tabular}




\section{Resident perceptions of crime}

Table 4. Outcome of perceived crime, predicted simultaneously by various types of official crime rates

\begin{tabular}{|c|c|c|c|c|c|c|c|c|c|c|c|c|c|c|c|}
\hline \multirow[b]{2}{*}{ Robbery } & \multicolumn{2}{|l|}{1976} & \multicolumn{2}{|l|}{1979} & \multicolumn{2}{|l|}{1983} & \multicolumn{2}{|l|}{1987} & \multicolumn{2}{|l|}{1991} & \multicolumn{2}{|c|}{1995} & \multicolumn{2}{|l|}{1999} & \multirow{2}{*}{$\begin{array}{r}\text { Average } \\
0.060 \\
(0.021)\end{array}$} \\
\hline & $\begin{array}{r}0.087 \\
(0.029)\end{array}$ & $* *$ & $\begin{array}{r}0.123 \\
(0.032)\end{array}$ & ** & $\begin{array}{r}0.078 \\
(0.031)\end{array}$ & $*$ & $\begin{array}{r}0.035 \\
(0.023)\end{array}$ & & $\begin{array}{r}0.033 \\
(0.015)\end{array}$ & $*$ & $\begin{array}{r}0.035 \\
(0.008)\end{array}$ & $* *$ & $\begin{array}{r}0.026 \\
(0.007)\end{array}$ & $* *$ & \\
\hline Aggravated assault & $\begin{array}{r}-0.013 \\
(0.029)\end{array}$ & & $\begin{array}{r}-0.017 \\
(0.028)\end{array}$ & & $\begin{array}{r}-0.031 \\
(0.024)\end{array}$ & & $\begin{array}{r}0.014 \\
(0.013)\end{array}$ & & $\begin{array}{r}0.033 \\
(0.012)\end{array}$ & $* *$ & $\begin{array}{r}0.022 \\
(0.007)\end{array}$ & $* *$ & $\begin{array}{r}0.023 \\
(0.008)\end{array}$ & $* *$ & $\begin{array}{r}0.004 \\
(0.017)\end{array}$ \\
\hline Murder & $\begin{array}{r}0.004 \\
(0.014)\end{array}$ & & $\begin{array}{r}0.008 \\
(0.015)\end{array}$ & & $\begin{array}{r}0.008 \\
(0.012)\end{array}$ & & $\begin{array}{r}0.017 \\
(0.007)\end{array}$ & * & $\begin{array}{r}0.009 \\
(0.007)\end{array}$ & & $\begin{array}{r}0.022 \\
(0.005)\end{array}$ & $* *$ & $\begin{array}{r}0.020 \\
(0.006)\end{array}$ & $* *$ & $\begin{array}{r}0.012 \\
(0.009)\end{array}$ \\
\hline Burglary & $\begin{array}{r}0.003 \\
(0.048)\end{array}$ & & $\begin{array}{r}0.051 \\
(0.055)\end{array}$ & & $\begin{array}{r}0.023 \\
(0.040)\end{array}$ & & $\begin{array}{r}-0.005 \\
(0.031)\end{array}$ & & $\begin{array}{r}0.013 \\
(0.015)\end{array}$ & & $\begin{array}{r}-0.023 \\
(0.009)\end{array}$ & * & $\begin{array}{r}-0.021 \\
(0.010)\end{array}$ & $*$ & $\begin{array}{r}0.006 \\
(0.030)\end{array}$ \\
\hline Motor vehicle theft & $\begin{array}{l}-0.022 \\
(0.033)\end{array}$ & & $\begin{array}{c}-0.111 \\
(0.040)\end{array}$ & $* *$ & $\begin{array}{r}0.006 \\
(0.029)\end{array}$ & & $\begin{array}{r}-0.019 \\
(0.022)\end{array}$ & & $\begin{array}{r}-0.043 \\
(0.018)\end{array}$ & $*$ & $\begin{array}{r}-0.005 \\
(0.008)\end{array}$ & & $\begin{array}{r}-0.011 \\
(0.007)\end{array}$ & $\dagger$ & $\begin{array}{r}-0.029 \\
(0.022)\end{array}$ \\
\hline Intercept & $\begin{array}{r}-0.022 \\
(0.209)\end{array}$ & & $\begin{array}{r}0.004 \\
(0.244)\end{array}$ & & $\begin{array}{r}-0.117 \\
(0.210)\end{array}$ & & $\begin{array}{r}0.352 \\
(0.159)\end{array}$ & * & $\begin{array}{r}0.238 \\
(0.067)\end{array}$ & $* *$ & $\begin{array}{r}0.280 \\
(0.041)\end{array}$ & $* *$ & $\begin{array}{r}0.196 \\
(0.037)\end{array}$ & $* *$ & $\begin{array}{r}0.133 \\
(0.138)\end{array}$ \\
\hline R-square & 0.519 & & 0.412 & & 0.241 & & 0.419 & & 0.476 & & 0.359 & & 0.401 & & 0.404 \\
\hline Number of households & 1,052 & & 2,060 & & 2,075 & & 3,255 & & 6,102 & & 13,118 & & 10,884 & & 5,507 \\
\hline Number of tracts & 139 & & 253 & & 245 & & 414 & & 1,332 & & 1,803 & & 1,525 & & 816 \\
\hline
\end{tabular}




\section{Resident perceptions of crime}

Table 5. Outcome of perceived crime, adjusted for individual-level bias, predicted by various types of official crime rate

\begin{tabular}{|c|c|c|c|c|c|c|c|c|c|c|c|c|c|}
\hline \multirow[b]{2}{*}{ Robbery } & 1976 & \multicolumn{2}{|l|}{1979} & 1983 & 1987 & \multicolumn{2}{|c|}{1991} & \multicolumn{2}{|l|}{1995} & \multicolumn{2}{|l|}{1999} & \multirow{2}{*}{\multicolumn{2}{|c|}{$\begin{array}{r}\text { Average } \\
0.064 \\
(0.021)\end{array}$ ** }} \\
\hline & $\begin{array}{r}0.094 \quad * * \\
(0.030)\end{array}$ & $\begin{array}{r}0.131 \\
(0.032)\end{array}$ & $* *$ & $\begin{array}{r}0.081 \quad * * \\
(0.030)\end{array}$ & $\begin{array}{r}0.036 \\
(0.023)\end{array}$ & $\begin{array}{r}0.039 \\
(0.015)\end{array}$ & $* *$ & $\begin{array}{r}0.039 \\
(0.008)\end{array}$ & $* *$ & $\begin{array}{r}0.030 \\
(0.007)\end{array}$ & $* *$ & & \\
\hline Aggravated assault & $\begin{array}{r}-0.012 \\
(0.028)\end{array}$ & $\begin{array}{r}-0.008 \\
(0.028)\end{array}$ & & $\begin{array}{r}-0.023 \\
(0.024)\end{array}$ & $\begin{array}{r}0.021 \\
(0.013)\end{array}$ & $\begin{array}{r}0.037 \\
(0.012)\end{array}$ & $* *$ & $\begin{array}{r}0.025 \\
(0.007)\end{array}$ & $* *$ & $\begin{array}{r}0.027 \\
(0.008)\end{array}$ & $* *$ & $\begin{array}{r}0.010 \\
(0.017)\end{array}$ & \\
\hline Murder & $\begin{array}{r}0.007 \\
(0.014)\end{array}$ & $\begin{array}{r}0.010 \\
(0.015)\end{array}$ & & $\begin{array}{r}0.013 \\
(0.012)\end{array}$ & $\begin{array}{r}0.021 \quad * * \\
(0.007)\end{array}$ & $\begin{array}{r}0.017 \\
(0.007)\end{array}$ & $*$ & $\begin{array}{r}0.025 \\
(0.005)\end{array}$ & $* *$ & $\begin{array}{r}0.023 \\
(0.006)\end{array}$ & $* *$ & $\begin{array}{r}0.017 \\
(0.009)\end{array}$ & $\dagger$ \\
\hline Burglary & $\begin{array}{r}-0.002 \\
(0.047)\end{array}$ & $\begin{array}{r}0.031 \\
(0.055)\end{array}$ & & $\begin{array}{r}-0.004 \\
(0.040)\end{array}$ & $\begin{array}{r}-0.031 \\
(0.032)\end{array}$ & $\begin{array}{r}0.002 \\
(0.015)\end{array}$ & & $\begin{array}{r}-0.027 \\
(0.009)\end{array}$ & $* *$ & $\begin{array}{r}-0.028 \\
(0.010)\end{array}$ & $* *$ & $\begin{array}{r}-0.008 \\
(0.030)\end{array}$ & \\
\hline Motor vehicle theft & $\begin{array}{r}-0.022 \\
(0.032)\end{array}$ & $\begin{array}{r}-0.109 \\
(0.039)\end{array}$ & $* *$ & $\begin{array}{r}0.015 \\
(0.029)\end{array}$ & $\begin{array}{r}-0.004 \\
(0.021)\end{array}$ & $\begin{array}{r}-0.040 \\
(0.018)\end{array}$ & $*$ & $\begin{array}{r}-0.006 \\
(0.008)\end{array}$ & & $\begin{array}{r}-0.011 \\
(0.007)\end{array}$ & $\dagger$ & $\begin{array}{r}-0.025 \\
(0.022)\end{array}$ & \\
\hline Intercept & $\begin{array}{r}-0.313 \\
(0.203)\end{array}$ & $\begin{array}{r}-0.229 \\
(0.243)\end{array}$ & & $\begin{array}{r}-0.319 \\
(0.210)\end{array}$ & $\begin{array}{r}0.149 \\
(0.159)\end{array}$ & $\begin{array}{r}-0.025 \\
(0.066)\end{array}$ & & $\begin{array}{r}0.023 \\
(0.041)\end{array}$ & & $\begin{array}{r}-0.063 \\
(0.038)\end{array}$ & $\dagger$ & $\begin{array}{r}-0.111 \\
(0.137)\end{array}$ & \\
\hline R-square & 0.598 & 0.461 & & 0.269 & 0.504 & 0.554 & & 0.393 & & 0.474 & & 0.465 & \\
\hline Number of households & 1,052 & 2,060 & & 2,075 & 3,255 & 6,102 & & 13,118 & & 10,884 & & 5,507 & \\
\hline Number of tracts & 139 & 253 & & 245 & 414 & 1,332 & & 1,803 & & 1,525 & & 816 & \\
\hline
\end{tabular}

${ }^{* *} p<.01$ (two-tail test), $* p<.05$ (two-tail test), $\dagger p<.05$ (one-tail test). Standard errors in parentheses. 
Resident perceptions of crime

Table 6. Including both violent crime and property crime in the models simultaneously to predict perception of crime

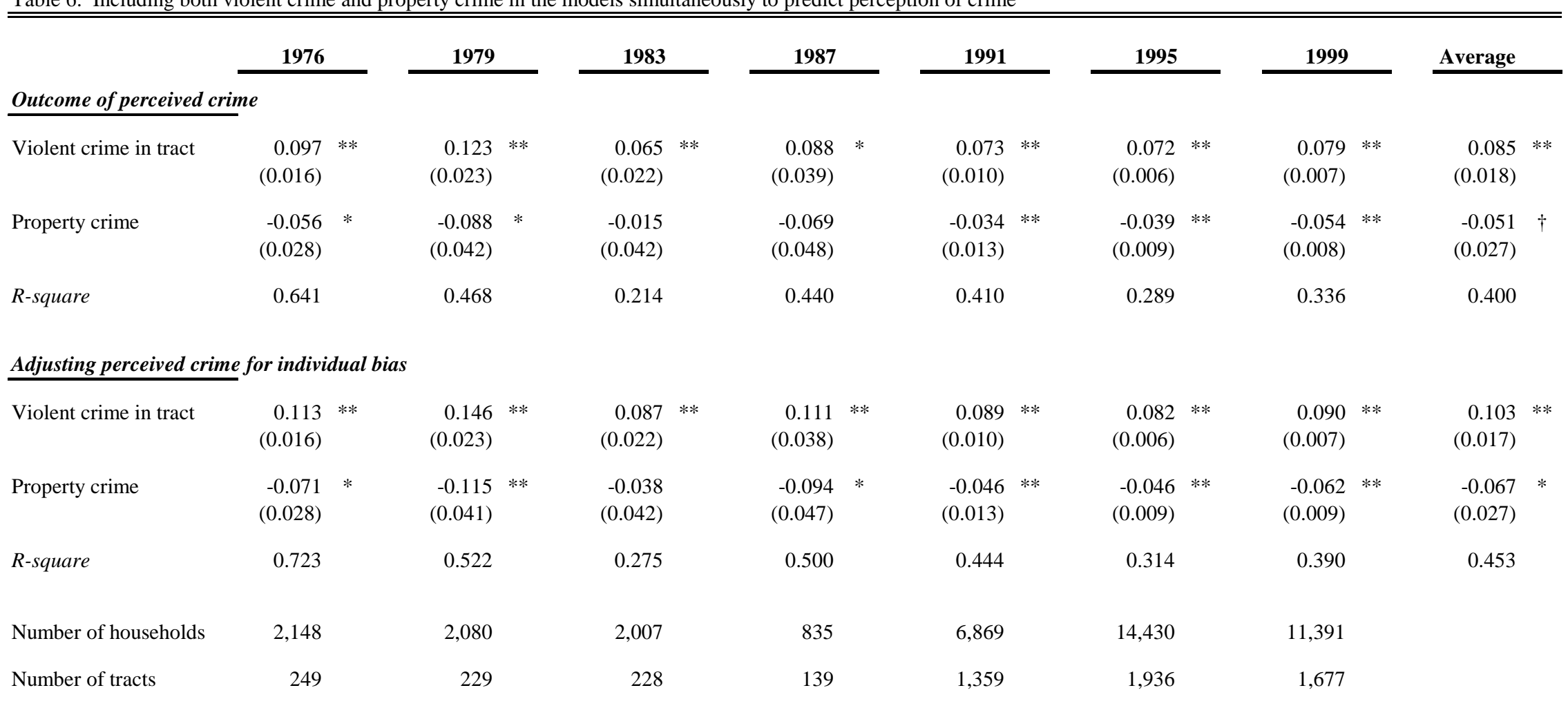

${ }^{* *} p<.01$ (two-tail test), ${ }^{*} p<.05$ (two-tail test), $\dagger p<.05$ (one-tail test). Standard errors in parentheses. 


\section{Resident perceptions of crime}

Table 7. Reporting the R-squares for models with outcome of perceived crime. Models using different combinations of official rates of various types of crime

\section{Ordinal outcome}

Violent crime

Violent crime and individual demographic chars

Violent and Property crime

Robbery, aggravated assault, murder, burglary, and

motor vehicle theft

Ordinal outcome adjusted for individual bias

Violent crime

Violent and Property crime

Robbery, aggravated assault, murder, burglary, and motor vehicle theft

Note: See Table 1 for characteristics of samples at each wave.

$\begin{array}{ccccc}\frac{1976}{0.573} & \text { a } & & 0.408 & \text { c } \\ 0.695 & \text { a } & & 0.513 & \text { c } \\ 0.629 & \text { a } & & 0.443 & d \\ & & & & \\ 0.519 & \text { b } & & 0.412 & f \\ & & & & \\ & & & & \\ 0.660 & \text { a } & & 0.468 & \text { c } \\ 0.737 & \text { a } & & 0.454 & d \\ & & & & \\ 0.598 & \text { b } & & 0.461 & f\end{array}$

\begin{tabular}{ll}
1983 & \\
\hline 0.214 & $\mathrm{~g}$ \\
0.314 & $\mathrm{~g}$ \\
0.238 & $\mathrm{~h}$ \\
0.241 & $\mathrm{i}$ \\
& \\
0.275 & $\mathrm{~g}$ \\
0.320 & $\mathrm{~h}$ \\
0.269 & $\mathrm{i}$
\end{tabular}

\begin{tabular}{cc}
1987 & \\
\hline 0.395 & $j$ \\
0.566 & $j$ \\
0.380 & $k$ \\
0.419 & $j$ \\
& \\
0.462 & $j$ \\
0.519 & $k$ \\
0.504 & $j$
\end{tabular}

\begin{tabular}{|c|c|c|c|}
\hline 1995 & & 1999 & \\
\hline 0.264 & $\overline{0}$ & 0.312 & $q$ \\
\hline 0.329 & 0 & 0.444 & q \\
\hline 0.319 & o & 0.422 & q \\
\hline 0.359 & $\mathrm{p}$ & 0.401 & s \\
\hline 0.284 & o & 0.362 & q \\
\hline 0.349 & o & 0.490 & q \\
\hline 0.393 & $\mathrm{p}$ & 0.474 & $s$ \\
\hline
\end{tabular}


Resident perceptions of crime

\section{Appendix}

For the aggregate crime data I used, it is necessary to place the data into common units over time. Since some of the data is aggregated to different units to begin with, this requires 1 ) placing the data into a common unit at a particular point in time (I used census tracts); and then 2) combining these census tracts over time into a common unit (I used 1980 census tracts since the American Housing Survey respondents are placed into 1980 tracts).

Placing the data into a common unit at a particular point in time

For instances in which the crime data were reported for geographic units other than census tracts, I calculated census tract crime data based on the proportion of the census tract constituted by each unit. This assumes a homogeneous condition in which the rate of crime is constant across the geographic units (such as police beats). Thus, I calculate the proportion of the tract contained within each police beat:

$$
X_{i}=\frac{1}{J} \sum_{j=1}^{J} X_{j}\left(P_{j i} / P_{i}\right)
$$

where $\mathrm{X}_{i}$ represents the crime rate in the tract which we are estimating, $\mathrm{X}_{j}$ represents the crime rate in the $\mathrm{j}=1$ to $\mathrm{J}$ police beats the tract overlaps, $\mathrm{P}_{j i}$ represents the population of police beat $j$ contained within tract $i$, and $\mathrm{P}_{i}$ represents the population of tract $i$. Thus, I compute the mean of the police beat crime rates weighted by the proportion of the tract contained within each police beat.

\section{Baltimore neighborhood data into tracts}

The Baltimore crime data comes from the "Crime Changes in Baltimore, 1970-1994” (CCIB) study. This study measures the amount of crime in various Baltimore neighborhoods over this period of time. Thus, I needed to place this neighborhood crime data into tracts. Fortunately, there is considerable overlap between these neighborhoods and census tracts in Baltimore. To determine the degree of overlap: 1) I obtained shape file information on the 
Resident perceptions of crime

boundaries of neighborhoods in 1990 from the Johns Hopkins website

(http://webapps.jhu.edu/census/); 2) I then visually reconciled this listing of neighborhoods with a hard copy map of the neighborhoods used in the CCIB study (contained in Taylor, Brower, and Drain 1979). It was necessary for me to collapse a few of the neighborhoods in the CCIB study to match them up with the neighborhoods mapped in 1990. Once reconciling the neighborhoods over time, I used ArcView to determine the degree of overlap between neighborhoods and tracts based on area, and used equations 1 and 2 above to place the crime data into tracts.

Combining these census tracts into a common unit over time

The second issue is taking into account tracts that change boundaries over time. Tracts generally change in one of two ways: 1) those experiencing population increases will split over time into multiple tracts; 2) those experiencing population decreases will consolidate over time into fewer tracts. ${ }^{12}$ To calculate the crime rate for a tract that split into two, I calculated a weighted mean value:

$$
X_{i}=\frac{1}{J} \sum_{j=1}^{J} X_{j}\left(P_{j} / P_{i j}\right)
$$

where $\mathrm{X}_{i}$ represents the crime rate at time two in the time one tract boundaries which we are estimating of the $i$-th tract at time one, $\mathrm{X}_{j}$ represents the crime rate in the $j=1$ to $\mathrm{J}$ tracts at time two lying within the time one boundary, $\mathrm{P}_{j}$ represents the population of the time two tract $j, \mathrm{P}_{i j}$ represents the population of tract $\mathrm{j}$ in the time one (i) boundaries, and we now are taking the mean value of the crime rate (since we are dividing by $\mathrm{J}$ ).

\footnotetext{
12 To place year 2000 tracts into 1990 tracts, I used the Census Tract Relationship File (Census 2000). To place 1980 tracts into 1990 tracts, I used the TIGER/Census Tract Comparability File (Census 1990). To place 1970 tracts in 1980 tracts, I used the 1980-1970 tract comparability file (Census 1987).
} 